\title{
Dukungan sosial dalam aktivitas jasmani remaja
}

\section{Social support in youth physical activity}

\section{Diky Hadyansah ${ }^{1}$}

${ }^{1}$ PJKR, STKIP Pasundan Cimahi, Jl. Permana 32B, Jawa Barat, 40512, Indonesia

\begin{abstract}
Abstrak
Dukungan sosial digambarkan sebagai faktor lingkungan sosial yang memberikan pengaruh besar dalam proses timbulnya perilaku aktivitas jasmani seseorang. Tujuan penelitian ini untuk mengetahui kontribusi dimensi dukungan sosial yang meliputi tangible support, appraisal support, self-esteem support and belonging support dalam menumbuhkan keinginan untuk melakukan aktivitas jasmani. Penelitian dilakukan menggunakan metode deskriptif korelasional, teknik survey melalui kuesioner dan skala sebagai alat pengumpul data. Hasil penelitian menunjukan, dimensi dukungan sosial memberikan kontribusi terhadap perilaku aktivitas jasmani sebesar 12\%. Kesimpulan besaran kontribusi parsial sebesar 3\% untuk appraisalsupport, 1,5\% untuk belonging support, $0,1 \%$ untuk tangible support, dan $2 \%$ untuk self esteem dan sisanya dipengaruhi oleh variabel lain.
\end{abstract}

Kata kunci: Aktivitas jasmani, Dukungan sosial.

\begin{abstract}
Social support is described as a social environmental factor that gives a big influence in the process of the emergence of a person's physical activity behavior. The purpose of this study was to determine the contribution of social support dimensions including tangible support, appraisal support, self-esteem support and belonging support in fostering a desire to carry out physical activities. The study was conducted using descriptive correlational methods, survey techniques through questionnaires and scale as a data collection tool. The results showed that the dimension of social support contributed to $12 \%$ of physical activity behavior. Conclusion, the amount of partial contribution is $3 \%$ for appraisalsupport, $1.5 \%$ for belonging support, $0.1 \%$ for tangible support, and $2 \%$ for self esteem and the rest is influenced by other variables.
\end{abstract}

Keywords: Physical activity, Social support.

\section{PENDAHULUAN}

Penurunan aktivitas jasmani di kalangan remaja menjadi fenomena yang sangat meresahkan di era teknologi ini. Allison, Adlaf, Dwyer, Lysy, \& Irving (2007) menjelaskan tentang adanya kesepakatan dalam beberapa literatur bahwa aktivitas jasmani menurun secara tajam selama masa remaja. Misalnya, di kalangan remaja Amerika, aktivitas jasmani menurun tajam dari usia 15-18 (Caspersen, Pereira, \& Curran, 2000). Penurunan tingkat jasmani ini memberikan kontribusi terhadap kenaikan tingkat obesitas globalyang telah meningkat secara substansial dalam 30 tahun terakhir(Young, Plotnikoff, Collins, 
Callister, \& Morgan, 2014). Tingkat aktivitas jasmani yang rendah menjadi faktor yang signifikan dalam meningkatkan prevalensi obesitas di Eropa (Cavil, Kahlmeier, \& Racioppi, 2006). Indonesia sebagai negara yang pertumbuhan ekonominya berada pada kondisi transisi tidak luput pula dari masalah ini (Gill, 2007). Menurut data hasil Riset Kesehatan Dasar (Riskesdas 2018), terdapat 31\% kasus obesitas sentral pada penduduk berusia di bawah 15 tahun. Kelebihan berat badan dan obesitas saat ini merupakan salah satu faktor utama yang memicu munculnya berbagai penyakit tidak menular, termasuk hipertensi, stroke dan diabetes mellitus atau kencing manis.

Aktivitas jasmani remaja telah teridentifikasi memiliki korelasi yang konsisten dalam pengembangan fisik, kesehatan mental, dan social (Sallis, Prochaska, Taylor, Hill, \& Geraci, 1999). Namun dampak dukungan social terhadap aktivitas jasmani remaja tidak banyak diukur. Padahal dukungan sosial telah dikutip memiliki korelasi penting dari aktivitas jasmani (King, 1994; Pender et al., 1994). Dalam teori kognisi social, dukungan sosial digambarkan sebagai faktor lingkungan sosial yang memberikan pengaruh besar dalam proses timbulnya perilaku aktivitas jasmani seseorang. Dukungan sosial berhubungan positif dan secara konsisten terkait dengan tingkat aktivitas fisik remaja dalam studi cross-sectional dan longitudinal (Aghdasi dkk., 2015). Hasil penelitian yang dilakukan di America Utara pada remaja wanita menunjukan bahwa dukungan sosial mempengaruhi aktivitas jasmani secara langsung ataupun tidak langsung melalui mediator efikasi diri (Motl, Dishman, Saunders, Dowda, \& Pate, 2007). Hal ini diperkuat oleh penelitian Laird, dkk. yang menyatakan bahwa dukungan sosial mempengaruhi perilaku aktivitas jasmani melalui peningkatan kinerja, efikasi diri, kesenangan, dan motivasi (Laird, dkk., 2018). Adapun dimensi dukungan sosial menurut Cohen \& McKay (1984 dalam Sarason \& Sarason, 1985) terbagi menjadi “Four categories of support functions were proposed: tangible support, appraisal support, self-esteem support and belonging support". Tangible support atau dukungan instrumental mengacu pada bantuan secara langsung. Tangible support ini berupa pemberian perlengkapan olahraga dan fasilitas transportasi, appraisal support berupa saran mengenai cara berolahraga dan diskusi terkait kegiatan olahraga yang diikuti self esteem support atau dukungan harga diri berupa perbandingan dengan orang lain dan penghargaan diri dan belonging support atau dukungan jaringan adalah dukungan yang dirasakan remaja berupa melakukan olahraga bersama dan mengatasi masalah bersama.Dalam hal ini, peneliti ingin melihat pengaruh dan besaran kontribusi yang diberikan oleh dimensi dukungan sosial terhadap aktivitas jasmani remaja. 


\section{METODE}

Penelitian ini menggunakan metode deskriptif korelasional. Pemilihan metode deskriptif korelasional ini berdasarkan pada tujuan penelitian yaitu ingin mengetahui kontribusi dimensi dukungan sosial dalam menumbuhkan keinginan melakukan aktivitas jasmani. Kontribusi disini merupakan arah hubungan dan besaran nilai yg dihasilkan dimensi dukungan sosial dalam menumbuhkan keinginan melakukan aktivitas jasmani di kalangan remaja.

Populasi dalam penelitian ini adalah Sekolah menengah atas (SMA) kelas XI di Kota Bandungusia 15-18 tahun dengan sampel penelitian 241 siswa yang tersebar dari empat sekolah negeri di Kota Bandung yaitu: SMAN 4, SMAN 6, SMAN 12, dan SMAN 15. Penentuan subjek penelitian menggunakan teknik cluster rondom sampling.

Teknik pengumpul data menggunakan survey melalui kuesioner dan skala. Instrument yang digunakan dalam penelitian ini terdiri dua instrument yaitu: skala dukungan sosial yang dikembangkan oleh peneliti dengan merujuk pada Cohen, Mermelstein, Kamarck, \& Hoberman (1985) dan instrumen yang digunakan dalam pengukuran aktivitas jasmani merujuk dan mengadaptasi pada instrumen Physical Activity Questionnaire for Adolescents (PAQA) yang dikembangkan oleh Kowalski, Crocker, \& Donen (1997).

Teknik analisis data yang digunakan adalah 1) Menghitung statistik deskriptif (Rerata, dan Simpangan Baku); 2) Melakukan uji asumsi klasik (uji normalitas, linearitas, multikorelasional, dan heterokedastisitas); 3) Melakukan analisis regresi linier berganda.

\section{HASIL DAN PEMBAHASAN}

Untuk memberikan gambaran umum mengenai distribusi data yang diperoleh dari penyebaran angket, maka data-data tersebut diolah dan dianalisis menggunakan program SPSS. Setelah dilakukan pengolahan data maka diperoleh rata-rata dan standar deviasi setiap variabel penelitian seperti pada tabel berikut ini:

\section{Tabel 1. Statistik Deskriptif Dukungan Sosial}

\begin{tabular}{cccccc}
\hline \multicolumn{5}{c}{ Descriptive Statistics } \\
\hline & $\begin{array}{c}\text { Jenis } \\
\text { Kelamin }\end{array}$ & N & Mean & $\begin{array}{c}\text { Std. } \\
\text { Deviation }\end{array}$ & $\begin{array}{c}\text { Std. } \\
\text { Error } \\
\text { Mean }\end{array}$ \\
\cline { 2 - 6 } & Laki-laki & 92 & 78.96 & 9.721 & 1.014 \\
$\begin{array}{c}\text { Dukungan } \\
\text { Sosial }\end{array}$ & Perempuan & 149 & 80.48 & 8.977 & .735 \\
\hline
\end{tabular}


Berdasarkan tabel 1 diperoleh nilai rata-rata tingkat dukungan sosial siswa lakilaki sebesar 78,96, dengan nilai simpangan baku sebesar 9,721. Sedangkan nilai rata-rata tingkat dukungan sosial siswa perempuan sebesar 80,48, dengan nilai simpangan baku sebesar 8,977.

Tabel 2. Statistik Deskriptif Aktivitas Jasmani Remaja

Descriptive Statistics

\begin{tabular}{cccccc}
\hline & Jenis Kelamin & $\mathrm{N}$ & Mean & Std. Deviation & Std. Error Mean \\
\cline { 2 - 6 } & Laki-laki & 92 & 39.52 & 8.495 & .886 \\
Aktivtas Jasmani & & & & & .703 \\
& Perempuan & 149 & 35.70 & 8.587 & \\
\hline
\end{tabular}

Berdasarkan tabel 2 diperoleh nilai rata-rata tingkat aktivitas jasmani remaja siswa laki-laki sebesar 39,52, dengan nilai simpangan baku sebesar 8,495. Sedangkan nilai rata-rata aktivitas jasmani remaja siswa perempuan sebesar 35,70, dengan nilai simpangan baku sebesar 8,587.

Tabel 3. Uji Linearitas Dukungan Sosial Anova Table

\begin{tabular}{|c|c|c|c|c|c|c|c|}
\hline & & & $\begin{array}{l}\text { Sum of } \\
\text { Squares }\end{array}$ & $\mathrm{df}$ & $\begin{array}{c}\text { Mean } \\
\text { Square }\end{array}$ & $\mathrm{F}$ & Sig. \\
\hline \multirow{5}{*}{$\begin{array}{c}\text { Aktivtas } \\
\text { Jasmani * } \\
\text { Dukungan } \\
\text { Sosial }\end{array}$} & \multirow{3}{*}{$\begin{array}{c}\text { Between } \\
\text { Groups }\end{array}$} & (Combined) & 5337,535 & 44 & 121,308 & 1,833 & ,003 \\
\hline & & Linearity & 2141,742 & 1 & 2141,742 & 32,363 & ,000 \\
\hline & & $\begin{array}{l}\text { Deviation from } \\
\text { Linearity }\end{array}$ & 3195,793 & 43 & 74,321 & 1,123 & ,294 \\
\hline & \multirow{2}{*}{\multicolumn{2}{|c|}{ Within Groups }} & 12971,154 & 196 & \multirow[t]{2}{*}{66,179} & & \\
\hline & & & 18308,689 & 240 & & & \\
\hline
\end{tabular}

Berdasarkan Tabel 3 hasil output ANOVA dari penghitungan SPSS di atas, menunjukkan bahwa nilai signifikasi Linearity 0,000. Karena signifikansi kurang dari alpha 0,05, maka dapat disimpulkan bahwa antara variabel aktivitas jasmani dan dukungan sosial terdapat hubungan linier.

Tabel 4. Uji Multikolinearitas

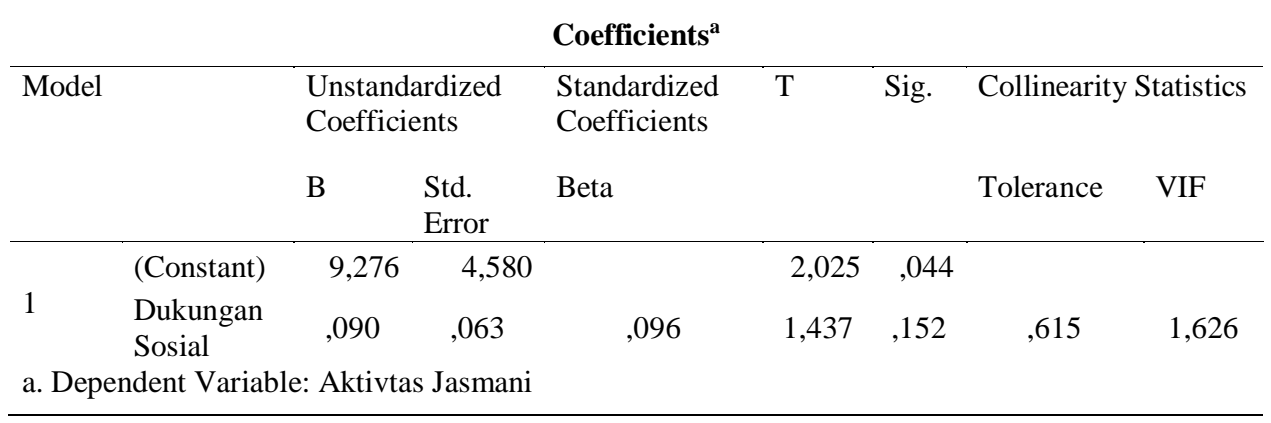


Berdasarkan Tabel 4 hasil output Coefficients dari penghitungan SPSS di atas, menunjukkan bahwa nilai VIF 1,626 untuk dukungan sosial, 1,819 untuk. Karena VIF variabel independent kurang dari 5, maka dapat disimpulkan bahwa pada model regresi tidak ditemukan adanya masalah multikolinearitas.

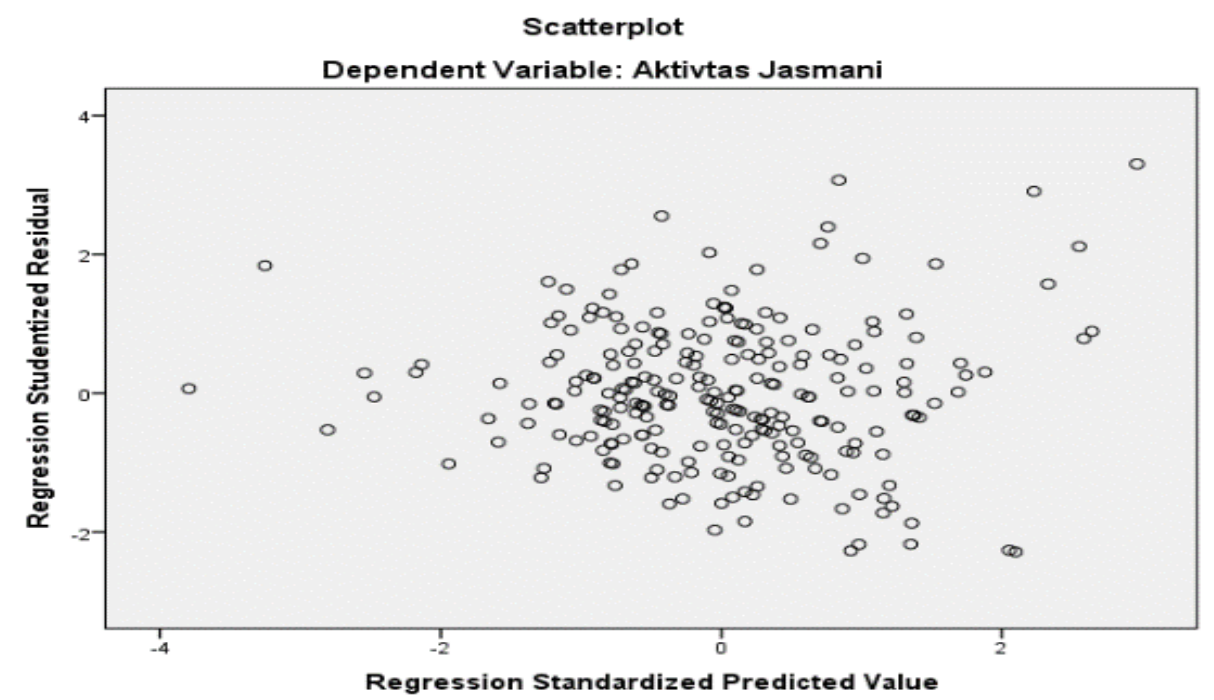

Gambar 1. Grafik Uji Heterokedastisitas

Berdasarkan gambar 1 di atas, terlihat bahwa titik-titik menyebar secara acak serta tersebar baik di atas maupun di bawah angka 0 pada sumbu Y. Hal ini disimpulkan bahwa tidak terjadi heterokedastisitas pada model regresi ini.

Berikut pengujian hipotesis menggunakan teknik anova kriteria nilai p yaitu jika nilai $\mathrm{p}$ lebih kecil dari a $(0,05)$ maka Ho ditolak. Adapun hasil output SPSS sebagai berikut :

Tabel 6. Hasil Uji Signifikasni ANOVA ${ }^{\text {a }}$ Appraisal, Belonging, Tangible dan Self Esteem Support

\begin{tabular}{|c|c|c|c|c|c|c|}
\hline & Model & $\begin{array}{l}\text { Sum of } \\
\text { Squares }\end{array}$ & df & $\begin{array}{l}\text { Mean } \\
\text { Square }\end{array}$ & $\mathrm{F}$ & Sig. \\
\hline & Regression & 2253,600 & 4 & 563,400 & 8,282 & $.000^{\mathrm{a}}$ \\
\hline 1 & Residual & 16055,089 & 236 & 68,030 & & \\
\hline & Total & 18308,689 & 240 & & & \\
\hline \multicolumn{7}{|c|}{$\begin{array}{l}\text { a. Predictors: (Constant), Self esteem, Tangible Support, } \\
\text { Belonging Support, dan Appraisal Support }\end{array}$} \\
\hline \multicolumn{7}{|c|}{ b. Dependent Variable: Aktivtas Jasmani } \\
\hline
\end{tabular}


Berdasarkan hasil perhitungan di atas, tampak nilai $\mathrm{p}$ lebih kecil daripada tingkat $\alpha$ yang digunakan (yaitu 0,05 ) atau $0,000<0,05$, sehingga Ho ditolak. Artinya Terdapat pengaruh yang signifikan antara appraisal support, belonging support, tangible support, dan self esteem support terhadap aktivitas jasmani remaja.

Tabel 7. Besaran Korelasi Simultan

Appraisal, Belonging, Tangible dan Self Esteem Support

\begin{tabular}{lllll}
\hline Model & $\mathrm{R}$ & $\mathrm{R}$ Square & Adjusted R Square & Std. Error of the Estimate \\
& & & \\
\hline 1 & $0,351^{\mathrm{a}}$ & 0,123 & 0,108 & 8,24803 \\
\hline
\end{tabular}

a. Predictors: (Constant), Self esteem, Tangible Support, Belonging Support, dan Appraisal Support

Berdasarkan hasil perhitungan tabel di atas, Nilai R2 (R Square) sebesar 0,123 atau $12 \%$. Hal ini menunjukan bahwa persentase korelasiSelf esteem, Tangible Support, Belonging Support, dan Appraisal Supportterhadap aktivitas jasmani sebesar $12 \%$. Sedangkan sisanya sebesar $88 \%$ dipengaruhi oleh variabel lain.

Tabel 8. Besaran Korelasi Parsial Appraisal, Belonging, Tangible dan Self Esteem Support

Appraisal Support Belonging Support Tangible Support Self Esteem Support

\begin{tabular}{lllll}
\hline R Square & $3 \%$ & $1,5 \%$ & $0,1 \%$ & $2 \%$ \\
\hline
\end{tabular}

Berdasarkan hasil perhitungan tabel di atas, Nilai R2 (R Square) sebesar 3\% untuk AppraisalSupport, 1,5\% untuk Belonging Support, 0,1\% untuk Tangible Support, dan $2 \%$ untuk Self esteem dan sisanya dipengaruhi oleh variabel lain.

Adapun hasil indeks koefisien korelasi setiap dimensi dukungan sosial yaitu antara appraisal support, belonging support, tangible support, dan self esteem support sebagai berikut : 
Tabel 9. Hasil Coefficients ${ }^{\mathrm{a}}$ Appraisal, Belonging, Tangible, dan Self Esteem

\begin{tabular}{|c|c|c|c|c|c|}
\hline \multirow[t]{2}{*}{ Model } & & \multicolumn{2}{|c|}{$\begin{array}{l}\text { Unstandardized } \\
\text { Coefficients }\end{array}$} & \multirow{2}{*}{$\begin{array}{c}\text { Standardized } \\
\text { Coefficients } \\
\text { Beta }\end{array}$} & \multirow[t]{2}{*}{ R Square } \\
\hline & & B & Std. Error & & \\
\hline \multirow{5}{*}{1} & (Constant) & 11,433 & 4,822 & & \\
\hline & $\begin{array}{l}\text { Appraisal } \\
\text { Support }\end{array}$ & 2,670 & 1,136 & 0,173 & $3 \%$ \\
\hline & $\begin{array}{l}\text { Belonging } \\
\text { Support }\end{array}$ & 1,863 & 1,109 & 0,120 & $1,5 \%$ \\
\hline & $\begin{array}{l}\text { Tangible } \\
\text { Support }\end{array}$ & 0,635 & 1,304 & 0,035 & $0,1^{*}$ \\
\hline & $\begin{array}{l}\text { Self Esteem } \\
\text { Support }\end{array}$ & 2,533 & 1,236 & 0,138 & $2 \%$ \\
\hline \multicolumn{5}{|c|}{ a. Dependent Variable: Aktivtas Jasmani } & \\
\hline
\end{tabular}

Berdasarkan hasil perhitungan tabel di atas. Dari sini dapat disimpulkan bahwa secara simultan bahwa variabel aktivitas jasmani remaja dipengaruhi oleh seluruh dimensi dukungan social dengan persamaan matematis : $\mathrm{Y}=\mathrm{a}+\mathrm{b} 1 \mathrm{X} 1-\mathrm{b} 2 \mathrm{X} 2+\mathrm{b} 3 \mathrm{X} 3+\mathrm{b} 4 \mathrm{X} 4$ atau $y=11,433+2,670+1,863+0,635+2,533$.

- Konstanta sebesar 11,433 menyatakan bahwa jika variabel independen dianggap konstan, maka nilai aktivitas jasmani remaja sebesar 11,433

- Koefisien regresi appraisal support sebesar 2,670 menyatakan bahwa setiap penambahan 1 nilai appraisal support, maka akan diikuti oleh bertambahnya 1 unit pada nilai aktivitas jasmani remaja

- Koefisien regresi belonging support sebesar 1,863 menyatakan bahwa setiap penambahan 1 nilai belonging support, maka akan diikuti oleh bertambahnya 1 unit pada nilai aktivitas jasmani remaja

- Koefisien regresi tangible support sebesar 0,635 menyatakan bahwa setiap penambahan 1 nilai tangible support, maka akan diikuti oleh bertambahnya 1 unit pada nilai aktivitas jasmani remaja

- Koefisien regresi self esteem support sebesar 2,533 menyatakan bahwa setiap penambahan 1 nilai self esteem support, maka akan diikuti oleh bertambahnya 1 unit pada nilai aktivitas jasmani remaja

Dukungan sosial menggambarkan sebagai tindakan yang ditunjukan untuk membantu seseorang mengadopsi dan menjaga latihan secara teratur. Dimensi Appraisal support mencakup memberikan nasihat atau panduan (mendapat saran dan berdiskusi). 
Dimensi ini memiliki korelasi sebesar 3\% lebih tinggi daripada yang lain. Keyakinan seseorang merupakan sumber utama secara psikologis dalam menangani bahaya yang dihadapi. Keyakinan ini terbentuk dari adanya dukungan social yang diterima. Dukungan social merupakan tahap pertama dalam proses penanganan stres dan banyak peneliti berspekulasi bahwa titik ini merupakan titik di mana dukungan social memainkan peran utamanya (cf. Cohen \& McKay, in pers; Wilcox, 1979 dalam Sarason \& Sarason, 1985). Dukungan sosial berperan dalam proses membentuk persepsi atau congnitive appraisal terhadap keadaan yang dihadapi. Hal ini terjadi ketika seseorang mengahadapi keadaan yang mengancam dirinya atau keadaan diluar kemampuannya. Persepsi atau congnitive appraisal terhadap keadaan sulit itu menjadi sangat penting. Proses congnitive appraisal dibagi kedalam dua proses : "event appraisal" dan "resource appraisal" (Sarason \& Sarason, 1985). Event appraisal merupakan evaluasi terhadap keadaan yang dihadapi, apakah mengancam atau berbahaya ; sedangkan resource appraisal merupakan serangkaian evaluasi kemampuan pengendalian yang layak dilakukan. Ketepatan event appraisal menjadi referensi dalam resource appraisal. Kedua proses itu membawa seseorang kedalam keadaan stress atau terancam. Namun dengan adanya stress, terjadi reevaluated sebagai sebuah informasi baru tentang solusi atau pengendalian diri menuju pencerahan. Perasaan adanya dorongan sosial akan menghasilkan reappraisal terhadap ancaman semakin berkurang. Maka hal utama yang dibutuhkan untuk membentuk persepsi atau congnitive appraisal adalah appraisal support yang berfungsi untuk membentuk persepsi atau congnitive appraisal tadi sehingga dimensi ini menjadi dimensi terkuat dalam pemberian dukungan social ini.

Selain itu, self esteem support berkontribusi $2 \%$. Dukunga ini melibatkan upaya untuk meningkatkan rasa kompetensi dan harga diri seseorang (perbandingan positif dengan orang lain dan penghargaan diri).Sebagaimana dukunga appraisal, dukungan self esteem juga berhubungan dengan penanggulangan stress yang tidak hanya berpusat pada masalah yang dihadapi (problem focus) melainkan juga pada sisi emosional (emotional focus). Dukungan sosial mampu mendorong usaha pengendalian melalui peningkatan sisi emosional dengan membangung self esteem atau self confidence dan juga melalui penyediaan informasi dan arahan yang untuk mengatasi ancaman dan membantu dalam merencanakan strategi penanggulangan. Resiliensi stress merupakan sebuah konsep yang menerangkan proses penanggulangan yang membantu seseorang untuk memelihara keadaan psikososial selama periode stress terjadi meliputi usaha kognisi dan perilaku untuk mengurangi atau menghilangkan kondisi yang tegang dan berkaitan dengan ketegangan 
emosional. Resiliensi stress bergantung kepada dua hal yaitu kekuatan personal (self confidence dan personal control) dan lingkungan (dukungan sosial).

Namun demikian, Peningkatan dukungan sosial yang dirasakan akan mendorong partisipasi remaja di kota Bandung aktif melakukan aktivitas jasmani. Dukungan ini sangat dibutuhkan mengingat berbagai hambatan yang dilalui untuk melakukan aktivitas jasmani seperti gaya hidup, ketersediaan waktu, sarana prasarana, dan ketertarikan remaja di zaman sekarang yang sudah mulai terbawa oleh era teknologi. Remaja sekarang lebih tertarik melakukan hal yang efisien sehingga menuntut diri untuk diam tidak melakukan aktivitas jasmani. Hal demikian itulah yang menjadikan peran dukungan sosial sangat diperlukan untuk membentengi diri melawan gaya hidup pasif.Seseorang yang menerima dukungan sosial dari orang tua, teman dan keluarga memiliki tingkat aktivitas jasmani yang tinggi (Mendonca, Cheng, Melo, \& Junior, 2014).

\section{KESIMPULAN}

Penelitian menunjukan bahwa dimensi dukungan sosial memberikan kontribusi terhadap perilaku aktivitas jasmani sebesar 12\%. Besaran kontribusi parsial sebesar 3\% untuk appraisalsupport, 1,5\% untuk belonging support, 0,1\% untuk tangible support, dan $2 \%$ untuk self esteem dan sisanya dipengaruhi oleh variabel lain.

\section{DAFTAR PUSTAKA}

Aghdasi, taghie M., Mobayen, F., \& Taghizadeh, Y. (2015). Effect Social Supports and Environmental Incentives on Physical Activities. Retrieved from http://www.euromed.uk.com/files/documents/w2.pdf

Allison, K. R., Adlaf, E. M., Dwyer, J. J. M., Lysy, D. C., \& Irving, H. M. (2007). The Decline in Physical Activity Among Adolescent Students. CANADIAN JOURNAL OF PUBLIC HEALTH, 98, 97-100.

Caspersen, C. J., Pereira, M. A., \& Curran, K. M. (2000). Changes in physical activity patterns cross-sectional age. MEDICINE \& SCIENCE IN SPORTS \& EXERCISE, 32(1), 1601-1609.

Cavill, N., Kahlmeier, S., \& Racioppi, F. (2006). Physical Activity and Health in Europe: Evidence for Action. Retrieved from http:// books.google.dk/books?id =ANPNhOiIggC

Cohen, S., Mermelstein, R., Kamarck, T., \& Hoberman, H. M. (1985). Measuring the functional components of social support. Journal of Applied Social Psychology, 13, 99-125, 127-139.

Gill, T. (2007). Young people with diabetes and obesity in asia. Growing epidemic. 
Diabetes Voice. 52, 20-22

King, A. C. (1994). Clinical and community interventions to promote and support physical activity participation. In R. K. Dishman (Ed.), Advancesin exercise adherence (pp. 183-212). Champaign, IL: Human Kinetics.

Kowalski, P. ., Crocker, P. R. ., \& Donen, R. M. (1997). Convergent validity of the Physical Activity Questionnaire for Adolescent. Pediatric Exercise Science, 9(August), 342-352.

Laird, Y., Fawkner, S., \& Niven, A. (2018). A grounded theory of how social support influences physical activity in adolescent girls. Int J Oual Stud Health Well-being. 2018; 13(1): 1435099.

Mendonca, G., Cheng, L. A., Melo, E. N., \& Junior, J. C. de F. (2014). Physical activity and social support in adolescents : a systematic review. Health Education Research, 1-18. http://doi.org/10.1093/her/cyu017

Motl, R. W., Dishman, R. K., Saunders, R. P., Dowda, M., \& Pate, R. R. (2007). Perceptions of Physical and Social Environment Variables and Self-Efficacy as Correlates of Self-Reported Physical Activity Among Adolescent Girls. Journal of Pediatric Psychology, 32(1), 6-12.

RISKESDAS, (2018). Hasil Utama RISKESDAS 2018. Jakarta.

Sallis, J. F., Prochaska, J. J., Taylor, W. C., Hill, J. O., \& Geraci, J. C.(1999). Correlates of physical activity in a national sample of girls and boys in grades 4 through 12 . Health Psychology, 18, 410-415.

Sarason, I. G., \& Sarason, B. R. (1985). Social Support: Theory, Research and Applicationse. Boston: Martinus Nijhoff Publ

Young, M. D., Plotnikoff, R. C., Collins, C. E., Callister, R., \& Morgan, P. J. (2014). Social cognitive theory and physical activity: a systematic review and metaanalysis, (13), 1-13. http://doi.org/10.1111/obr.12225 